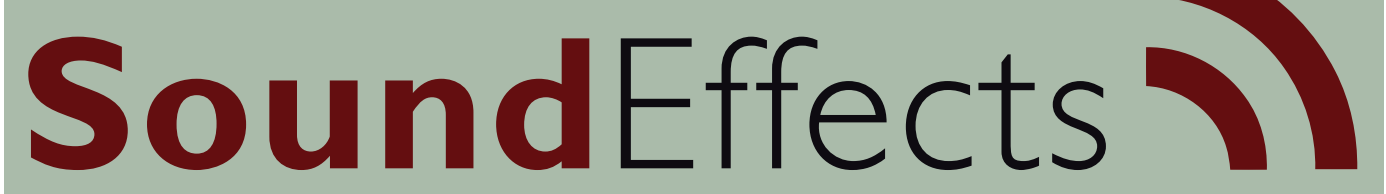

An Interdisciplinary Journal of Sound and Sound Experience

\title{
Morten Michelsen
}

\section{Michael Jackson's sound stages}

\author{
Dr. Morten Michelsen \\ Associate Professor of Musicology \\ University of Copenhagen \\ momich@hum.ku.dk
}


'You can actually paint sonic panoramas with musical sounds'. (Swedien, 2003, p. 145) ${ }^{1}$

\begin{abstract}
In order to discuss analytically spatial aspects of recorded sound William Moylan's concept of 'sound stage' is developed within a musicological framework as part of a sound paradigm which includes timbre, texture and sound stage. Two Michael Jackson songs ('The Lady in My Life' from 1982 and 'Scream' from 1995) are used to: a) demonstrate the value of such a conceptualisation, and b) demonstrate that the model has its limits, as record producers in the 1990s began ignoring the conventions of stereo recording's illusion of three dimensions and reached for a severing of the intimate relations between sound and Euclidic space.
\end{abstract}

In the last one and a half decades interest in the analysis of recorded sound has grown immensely. The 1990s and the years around 2000 saw a couple of seminal texts published: William Moylan's The Art of Recording (1992 and later editions) was the first extended discussion of how we may talk about recorded sound, and Serge Lacasse's thesis on vocal staging (2000) and Albin Zak's Making Tracks (2001) took up the gauntlet. Since then we have seen The Research Centre for the History and Analysis of Recorded Music take up residence in London in 2004 and the Art of Record Production conference take place each year since 2005 and the likewise named journal be published since 2007. Needless to say, this has been supported by a growing research community, and the field of study has been summarised by Simon Zagorski-Thomas in his article 'The Musicology of Record Production' (2008).

In this article I would like to address and connect two topics: the music-analytical concept of the sound stage and the actual sound of Michael Jackson's music. Moylan developed the concept of the sound stage and defined it as follows: 'The sound stage is the location within the perceived performance environment, where the sound sources are perceived to be collectively located, as a single ensemble' (1992, pp. 207-208). Lacasse's concept of staging is equally very useful, as his definition may be extended to encompass other sounds than vocals, ${ }^{2}$ and other popular music scholars have contributed to methodological and theoretical explorations of these topics (e.g. Zak, 2001; Zagorski-Thomas, 2005 and 2006; Walther-Hansen, 2009) and to historical studies (e.g. Katz, 2005; Doyle, 2005). Film studies has contributed quite extensively to the analytical exploration of sound, whether musical or not, ${ }^{3}$ and, of course, acoustics has been doing analytic work all the time, even though their results only seldom have been of any direct use to music analysts. Also, the best of the many text books on recording techniques have been an inspiration to 
the music-analytical development - Moylan's book being one of these. On the other hand, there is to my knowledge next to no literature discussing the music or the sound of Michael Jackson in any detail, even though his videos and his image issues have attracted much scholarly attention. ${ }^{4}$

Related to these two topics - sound and Michael Jackson's music - is a more fundamental problematic, namely how to talk about sound. Even though some highly relevant work has been done by the researchers mentioned, we still need to develop concepts and methods that are meaningful when such a notoriously elusive aspect of our musical everyday life is called upon by discourse. In the words of Moylan, with regard to the spatial aspect:

Space in music can be profoundly important. These qualities can create a context for the song and its materials, be used to enhance musical ideas and the instruments and voices that present them, can even function as musical materials, and much more. Still, the breadth and the significance of their role in recorded music is not defined or fully understood. (Moylan, 2008)

The main aim of such work is to open up sound - whether musical, non-musical or somewhere in-between - for discussion. And, not least, for discussions about musical meaning production. For this purpose I will present what I have called a sound parameter which includes the sound stage. Later on I will demonstrate the sound stage as used by Michael Jackson and his producers, engineers and programmers in two recordings. The first is a very good example of a conventional, three-dimensional music production, and the second tests the limits of analytical models based on the concept of the sound stage.

\section{A sound parameter}

Some years ago I proposed a sound parameter with the intention of making it possible for others than recording specialists to articulate observations on recorded sound. Taking my cue from Jan LaRue (1970), it was intended as an extension of the traditional series of music-analytical parameters (melody, harmony, rhythm and form) and as a 'tool' for music analysts approaching music from a listener's point of view, not that of the producer's - whether musician, recording engineer or record producer (Michelsen, 1997, pp. 91-142). Moylan's The Art of Recording (1992 and later revised editions) has been the main inspiration for constructing the parameter, and most of the separate elements are inspired by him as well, though somewhat revised, as his intention is to train recording engineers, and the present intention is to analyse music. The sound parameter may be systematised as comprising three aspects containing a series of elements: 


\begin{tabular}{|c|c|c|}
\hline Timbre & Texture & Sound Stage \\
\hline $\begin{array}{l}\text { Instrumentation: } \\
\text { Instruments (includ- } \\
\text { ing machines and } \\
\text { programs) } \\
\text { Effects } \\
\text { Playing techniques } \\
\text { Register }\end{array}$ & $\begin{array}{l}\text { Distribution in the } \\
\text { frequency spectrum }\end{array}$ & $\begin{array}{l}\text { Relative dimensions } \\
\text { of the sound stage } \\
\text { Perceived local perform- } \\
\text { ance environment (i.e., } \\
\text { for each sound source) } \\
\text { Perceived global per- } \\
\text { formance environment }\end{array}$ \\
\hline $\begin{array}{l}\text { Dynamics (perform- } \\
\text { ance intensity) }\end{array}$ & $\begin{array}{l}\text { Dynamics (level } \\
\text { in the mix) }\end{array}$ & $\begin{array}{l}\text { Organisation of the } \\
\text { sound sources on } \\
\text { the sound stage: }\end{array}$ \\
\hline $\begin{array}{l}\text { Metaphors: } \\
\text { Common (or inter- } \\
\text { subjective) } \\
\text { Subjective }\end{array}$ & $\begin{array}{l}\text { Metaphors: } \\
\text { Common (or inter- } \\
\text { subjective) } \\
\text { Subjective }\end{array}$ & $\begin{array}{l}\text { Left/right (left } \\
\text { and right) } \\
\text { Front/back } \\
\text { Up/down } \\
\text { Movements }\end{array}$ \\
\hline $\begin{array}{l}\text { Comparisons to } \\
\text { other music } \\
\text { (tends towards the } \\
\text { melody parameter) }\end{array}$ & $\begin{array}{l}\text { Comparisons to } \\
\text { other music } \\
\text { (tends towards har- } \\
\text { mony, rhythm, and } \\
\text { form parameters) }\end{array}$ & \\
\hline
\end{tabular}

Figure 1: A sound parameter (Michelsen, 1997, p. 124)

The first two columns, timbre and texture, are quite conventional. What may be new are the two different sets of dynamics: the dynamics at the point of recording and the dynamic level in the mix. Also, metaphors seem to be extremely helpful tools when talking about sound, and their workings may be understood and theorised with reference to research made in the tradition following the works of George Lakoff and Mark Johnson (Lakoff \& Johnson, 1980; Johnson, 1987; see also Michelsen, 1997, pp. 65-79). Comparisons to other music seem to be a great help as well when trying to explain what something sounds like, thus avoiding language to some extent.

The third column might merit a few more words, as it conceives of the sound stage as a three-dimensional illusionary space constructed in recording and mixing studios and mediated though conventional stereo or surround sound systems or headphones. ${ }^{5}$ The horizontal dimension is defined by the stereo perspective's left/ 
right and controlled using the panning knob, the depth dimension by the perceived distance between sound source and listener, ${ }^{6}$ and the vertical dimension by frequency distribution. The vertical dimension is somewhat contested. Moylan states that the sound stage has only two dimensions, width and depth (Moylan, 1992, p. 207), but accepts that the pitch area may be conceived of as a space, even though it cannot be measured (ibid., pp. 27, 174). Other writers like Albin Zak accept this vertical dimension as defined by frequencies (or rather, frequency bands). Nevertheless, the vertical dimension is more abstract - some would say metaphorical (e.g. Zagorski-Thomas, 2006, p. 2) - than the two other dimensions, even though Western music culture has quite clear perceptions of which sounds are above which.

The dimensions of the sound stage cannot be established precisely. Relative sizes can be given (small, medium or big), but metaphors will be needed to give a sense of size and materiality, e.g. cathedral, concrete storage room, garage or heavily damped living room. And Euclidic metaphors are not always enough. Moylan argues that the sound stage is constructed either by giving each sound source its own acoustic characteristics (the perceived local performance space) or by adding general acoustic characteristics in the mixing process (the perceived global performance space). The two principles might be mixed as well. In the first case the listener unconsciously orders the sounds in a certain acoustic relationship, based on the most dominating sound sources (Moylan, 1992, p. 234-239). The fact that different local performance spaces can exist within a global performance space is called the illusion of space within space. The space of single sound sources can be placed on a continuum from a precise point to larger, more or less well-defined areas. The exact placement of distance or place with regard to right/left is quite imprecise, but placing sound sources and their environments in relation to each other makes up for this.

The sound parameter suggested here is quite systematic. Albin Zak mentions most of the elements named in this context, but he is less rigid, partly because his intention is to describe the recording process from recordists' perspective, ${ }^{7}$ and partly because he wants to stress the interrelatedness of all aspects of the music. I mention this in order to point out that Zak, being both a recordist and a musicologist, basically agrees that the elements of the present sound parameter are relevant and that it corresponds roughly to his findings. I might add that some acousticians as well seem to accept the three-dimensional stage metaphor as a useful way of conceptualising the spatial qualities of recorded sound. The same researchers even accept talking about it in more or less subjective ways (Rumsey, 2002; Toulson, 2006).

\section{'The Lady in My Life'}

Michael Jackson's recording of 'The Lady in My Life', the last track on the 1982 album Thriller, is a good example for demonstrating how this works in analysis. ${ }^{8}$ The song 
was composed by Rod Temperton, produced by Quincy Jones and Michael Jackson and recorded by Bruce Swedien. The musicians are Greg Phillinganes (Fender Rhodes), Michael Boddicker (emulator), Paul Jackson (guitar), Louis Johnson (bass) and the three Toto members David Paich, Steve Porcaro and Jeff Porcaro, the first two on synthesisers, the last one on drums. I will single out Jackson's vocal in order to demonstrate the discussion of timbre.

In this song Michael Jackson's range goes from a to a' with small detours below and above, and the diction is always very clear. In verses and refrains he sings in a straight manner with small dynamic inflections, but applies a small amount of vibrato at phrase endings. In the contrast part he applies glottal stops as well. With regard to performance intensity, he sings still louder; there are three dynamic levels in verse, bridge and refrain, respectively (from crooning to a loud, nasal head resonance). The loudest level is used in the two long codas. The local performance space changes accordingly, as Jackson sings still closer to the microphone (the sibilants in the 5.000-8.000 Hertz area become clearer). In the codas he takes up vocal techniques and expressions like belting, glissando, falsetto, vocal noises and heavy breathing.

There are two voice personas present: the boyish, harmonious ballad singer of the first part and the more teenage-like, compressed and noise-filled soul singer with a few falsetto and 'uh-oh' outbursts of the second part. The difference is clear, but not striking, and it is supported by the rhythmical feeling (legato versus a bit more staccato, full phrases versus short outbursts). Metaphorically speaking one could talk about a rhythmic change from floating to abrupt, a rhetorical change from eloquent to unarticulated and a timbral change from the controlled tremble of the vibrato to the falsetto's abundance of feeling. In general, there is a movement from controlled to uncontrolled, but also from the naive (clear diction and pitch) to sensual knowledge (affectionate, fondling, begging). At the same time, the choir (also sung by Jackson) sticks to the soft sounds during the soul singing.

The six bar introduction (the first 22 seconds) can show some aspects of the song's texture (the combined instrumental timbres) as illustrated in figure 2 . The $x$ axis denotes time measured in bars and the y axis the relative placement of instruments according to main frequencies. The coloration denotes four dynamic levels, ranging from $p p$ to $f$.

Often variations in texture and sound stage placement contribute to underline the song's form (in general, time might be considered the fourth dimension of the sound stage). This happens in several ways in this quite simple song. First, vocals and accompaniment are dynamically intensified, when the first verse takes over from the intro. Second, the primary vocal changes its dynamics, its local performance space and its location on the sound stage. These changes can be heard at the intersections of the first verse and the bridge (0:46) and again at the intersection of the bridge and the first refrain (0:59). ${ }^{9}$ Third, the accompaniments for the two 


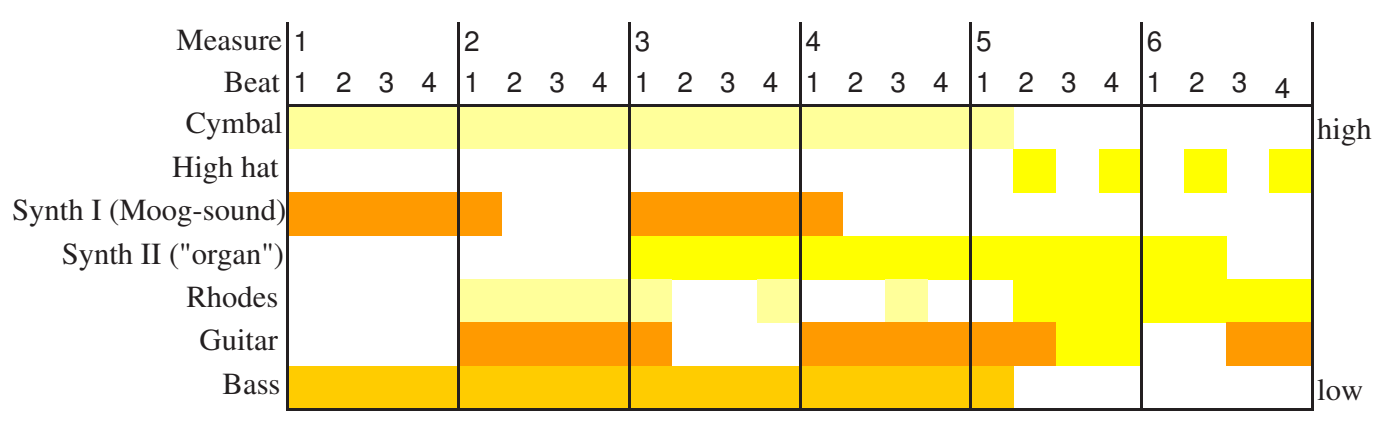

Colour legend: $\quad f \quad m f \quad p \quad p p$

Figure 2: 'The Lady in My Life', texture, bars 1-6

codas (2:38-3:42 and 3:43-4:56) reverse the dynamic intensification, thus creating a dynamic curve for the entire song.

Apart from these details, this is quite an ordinary, if very well done, stereo recording from a sound stage perspective. In the sketch below (figure 3) the relational size and the placement of sound sources' local performance spaces can be seen.

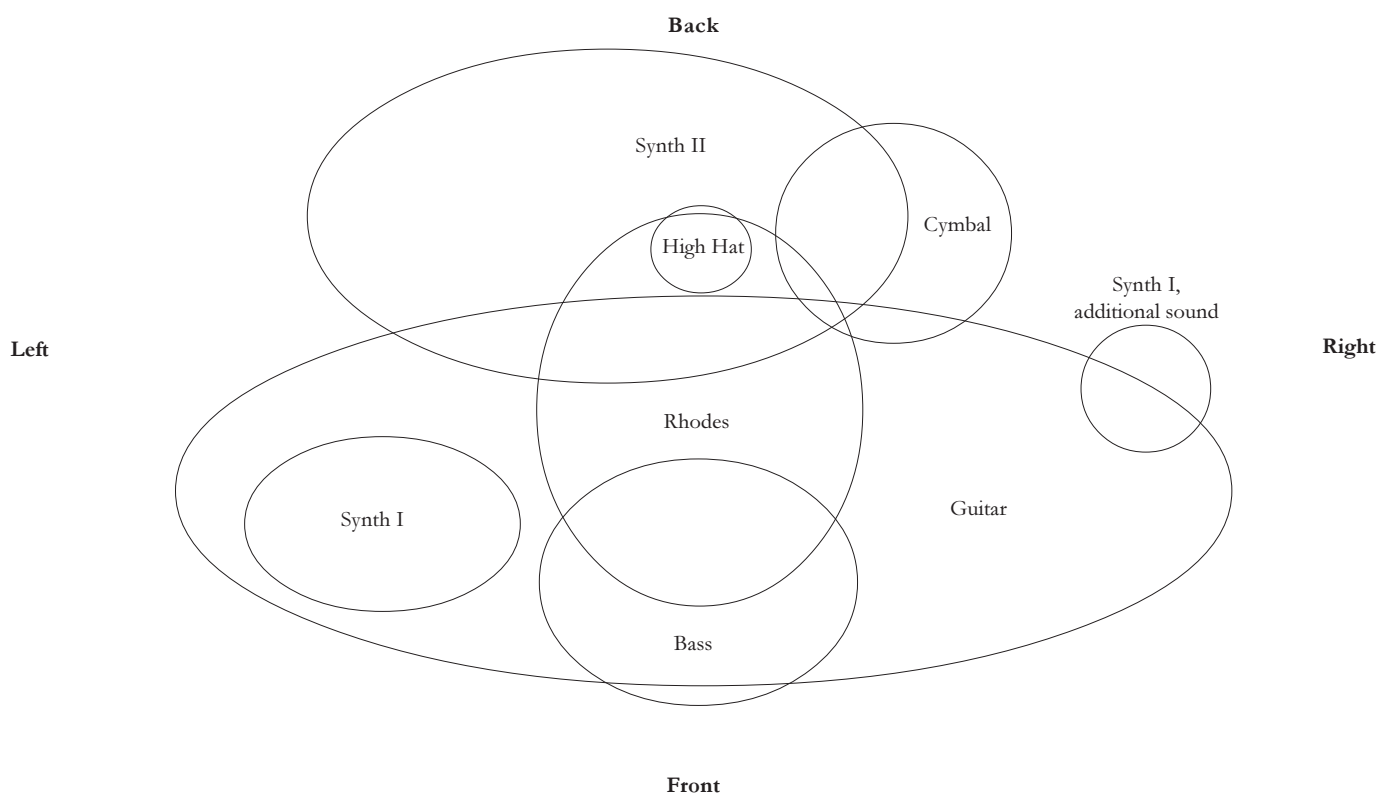

Figure 3: 'The Lady in My Life', sound stage, bars 1-6

The sound stage in figure 3 is seen from above (the texture in figure 2 shows the vertical distribution). Bass, percussion and Fender Rhodes are placed at the front of relatively small, perceived local performance spaces (much high frequency information), while guitar and synth II are placed further back in their larger, local spaces 
(partly due to the amount of delay). The high frequencies and the very clear, if soft attacks on most nodes contribute a certain crispness to the overall texture. The sound stage is quite spacious, and there is plenty of room for each sound source, also the ones following later (voice(s), synth-trumpet and synth-strings). The dynamics at the point of recording are kept low, and the figure shows the dynamics in the mix.

The bass and the time-marker on the second and fourth beat are placed conventionally in the middle, and the Rhodes has the role of soloist because of its staging. The guitar has a rather large, local performing space, which helps to define the global performing space. The synthesiser sounds do that as well by being placed right, left and to the back. The synth I sound seems to consist of two separate sounds placed left and right, triggered by the same playing impulse. In general, the placement of the sound sources in relation to each other is clear and helps to establish a sense of perspective. Also, the order of the sound sources' appearance helps build the sound stage. In bar one ground and back are established, and in bars three and five synth II establishes a still higher ceiling and a back cloth still further away. Synth I and guitar might be considered soloists, but they are not convincing in that role. Only the appearance of the Rhodes in the right place in bar five constitutes a soloist - but one that still leaves a lot of space for Jackson's vocal in the following.

I consider such sound stage constructions one of the basic conventions in stereo recording practices. It was developed during the 1960s, and the changes in The Beatles' recordings during that decade are a particularly good demonstration of how bass, drums and solo vocals came to be placed at the centre, while guitars, keyboards and other accompanying instruments together with backing singers were placed to the left or right or in the background. Since then the basic placement plan has hardly changed, while the clarity of the three-dimensional, illusory space has changed quite a lot. Different styles have used space differently, ${ }^{10}$ and record producers have their individual 'sound signatures' as well.

As soon as conventions are doing their cultural work, somebody will tinker with them or even try to overthrow them. Through the last 50 years of recording history there have been numerous examples of this, many of them fascinating, but they have not managed to establish general norms different to the sound stage. Nevertheless, discussions of sound need to take such experiments into account, partly because there are so many of them, and partly because the analysis of experiments might refine the way we analyse music recorded adhering to the conventions. We need not stray away from the Jackson repertoire in order to find such experiments. 'Scream' from the 1995 album HIStory is one example. 


\section{'Scream'}

From Thriller onwards to his death, Jackson himself, several producers and recording technicians had access to state of the art equipment (sometimes even prototypes ${ }^{11}$ ), to unlimited studio time and to highly inventive programmers. Combined with their own, often innovative practices this has resulted in many different constructions of illusionary spaces, some traditional, some quite strange. HIStory consists of two CDs, one containing a selection of greatest hits and one containing new recordings. The second is a veritable catalogue of sound stages, and the 'Scream' sound stage is probably the most outstanding. By 1995 the Jackson recording team had changed from analogue to digital recording equipment (Swedien, 2003, p. 154). This made it possible to shape the sound stage in much more detail than before.

The main principle for the construction of the 'Scream' sound stage seems to be an attempt to intimidate the listener in the same way that the song's persona is intimidated (or pressured), presumably by the gutter press (cf. Michelsen, forthcoming) - and to create a great dance track. That is, I take it that the producers and the technicians have tried to establish an anaphone to the lyrics. In the 'Scream' introduction this intimidation is attained in several different ways: spatial confusion, distortion, very small local performance spaces and the placement of certain sounds to the forefront of the stage.

Below is the texture for the first 19 seconds (there is no regular pulse). The 'instrumentation' is quite uncommon, suggesting a sound collage rather than a normal piece of music.

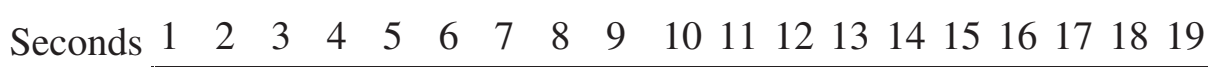

Clear synth-sound

Guitar feedback

Explosion

Cup against plate

MJ: hoarse scream

Glass shattering

LFDS

Kick drum

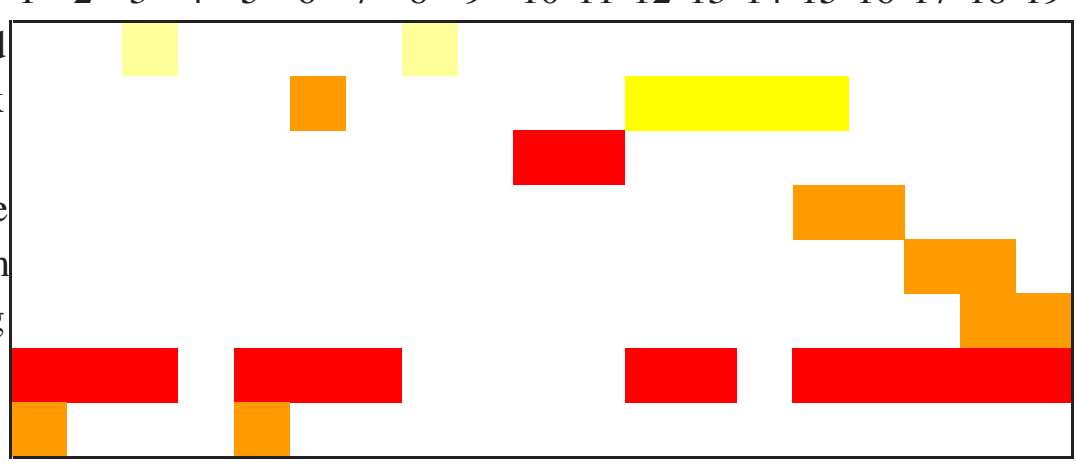

Colour legend
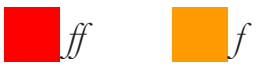

$p p$

Figure 4: 'Scream', texture, Intro I (0:00-0:19)

The first sound we hear is a low frequency, heavily distorted and slightly restricted sound (LFDS) (because the top frequencies are cut off), placed at the mid forefront. 
It is almost thrown in the face of the listeners, most of whom would certainly not expect such an aural gesture in a Michael Jackson recording. The local performance space is impossible to judge, but it is spread between left and right, very much to the front, and not stretching very far back. The LFDS is supported by a kick drum at the first two onsets. After two seconds a clear synth sound defines a large global performing space by appearing in the back. Although this to a certain extent defines a three-dimensional space, the stark contrast between LFDS and the clear synth sound is what sticks and thus contributes to the confusion about spatial definition. The relation between the two sounds might also be construed as one sound (source and reverb) because of the temporal and spatial relations (one following the other, front/back). Acoustic conventions make this probable, but the actual sounds make it improbable, thus further contributing to the confusion.

The explosion contributes to the confusion as explosions are conventionally used to blow up rooms or spaces. The guitar feedback - a barely controlled sound maybe indicating something or someone being on the brink of losing it - once again demonstrates a space behind the all-dominating LFDS, ${ }_{12}^{12}$ while the cup and saucer sound suddenly establishes a totally different place. Everyday sounds placed among more or less musical sounds and explosions stick out, and often they have very specific connotations - here maybe 'kitchen', 'having a chat', 'peace and quiet'. Nevertheless, incongruity is used once again.

Michael Jackson's hoarse scream is somewhat distorted, the frequency range compressed, and the local performance space is small. The effect is somewhat claustrophobic, and the panning of the local space from right to left contributes to the spatial disorientation. The last sound source, the shattering of glass, is placed mid-back and is panned left to right just after the scream panning in the opposite direction. Again two sounds following each other in a distinct pattern suggests a relation - Michael Jackson thrown through a window or Michael Jackson smashing a window in anger?

In this short description of the first 19 seconds of 'Scream' the placement of sound sources has been related to the three-dimensional sound stage, implying that this example is a deviation from a convention demonstrated in 'The Lady in My Life'. It proved possible to place the sound sources within a three-dimensional, if fragmented space. A sound stage sketch would look somewhat like this (see Figure 5 on next page).

Like the 'Lady ..., the sound stage of 'Scream' changes through time. In the second part of the introduction the beginning of a steady pulse helps to establish a solid base (a 'floor', so to speak), and the vocals in the following two verses (Michael and Janet Jackson's solo voices), the bridge (solo voices and chorus) and the refrain help (harmonised solo voices) open up the space still more. Although the harmonised solo voices contribute to the definition of a larger space, they also contribute to the 


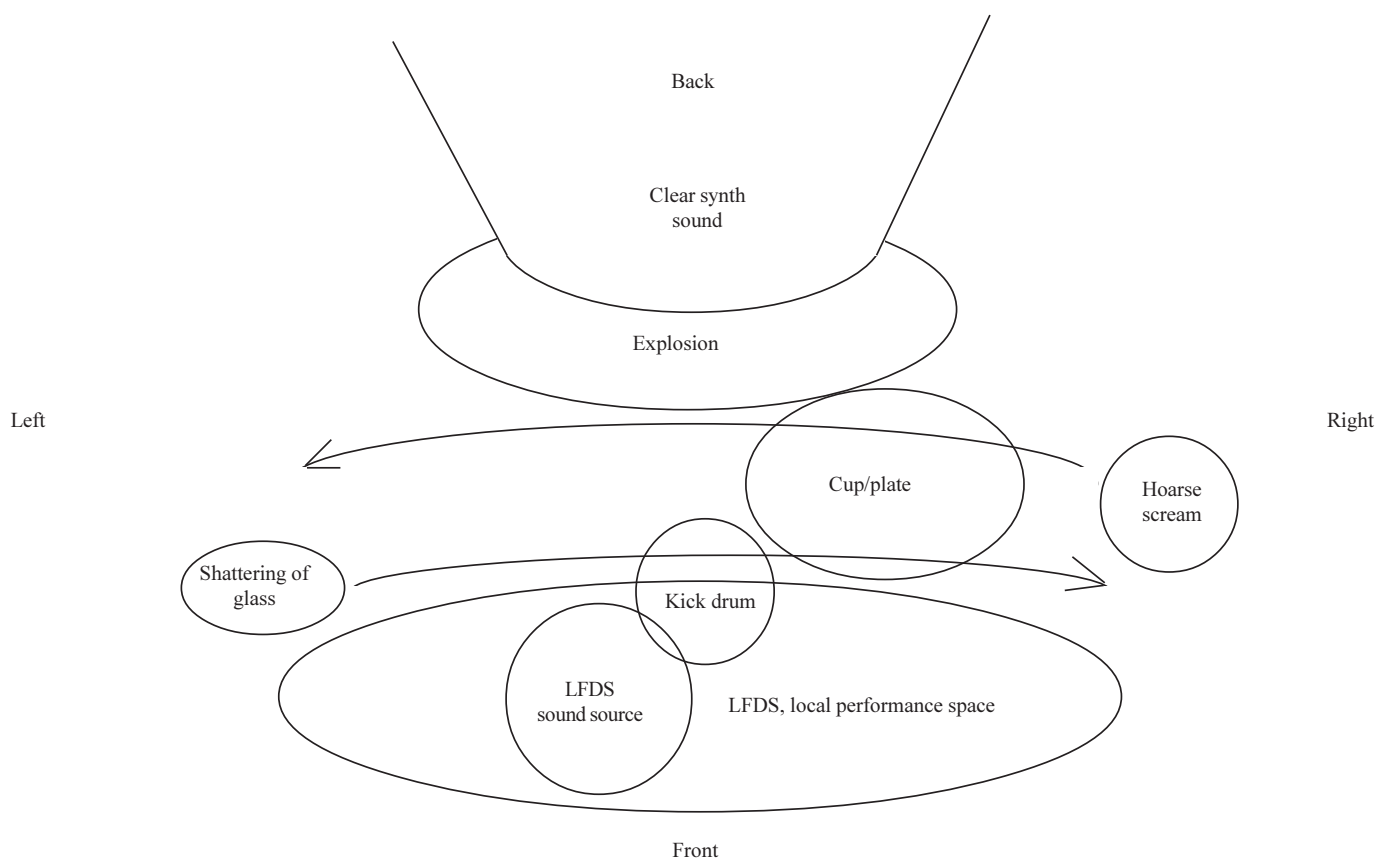

Figure 5: 'Scream', sound stage, Intro I (0:00-0:19)

spatial confusion because of the artificiality of their local performing spaces. The consonants $s$ and $p$ sound as if uttered right next to your ear, while other parts of the sound seem a bit further away (with each repeat the refrain's vocal textures become still denser). The spatial density is underlined by its disappearance in the contrast section beginning at 2:57 and in the second part of the guitar solo at 3:19. Because of the few sound sources, the sound stage is almost transparent and thus functions as a stark contrast first and foremost pointing to the great textual density of the rest of the song.

The point of this short analysis is that the sound sources contribute to the questioning of the sound stage, both from a technical, a perceptive and a hermeneutic point of view - their connotations clash, maybe suggesting a surreal scenario: a narrative that contains explosions, kitchen chats, screams, smashed windows and skewed perspectives and which never becomes coherent. It is possible to draw a sketch of the sound stage, but it is quite imprecise and varies depending on the playback equipment. A reason for not drawing this sketch at all could be that the whole point may be that the illusionary, three-dimensional space is fragmented and, thus, impossible to imagine as a Euclidean space and to represent in a simple two-dimensional model. 


\section{Conclusions}

Even though the general layout of the 'Lady ...' sound stage is to some extent naturalistic (that is, it can be imagined as a three-dimensional space imitating a live band set-up), some of the sound sources are in fact not that naturalistic, in part because they have been modified, using an equaliser to change their normal frequency pattern (the cymbal is a good example). Also, later on in the song, the backing choir, consisting of multiple Jacksons, is placed in a local performance space that bears no resemblance to known spaces. Nevertheless, this does not change the overall impression of an ordinary band set-up recorded in conventional stereo, and the recording is a good example of a 'naturalistic' recording aesthetic that communicates the impression of a three-dimensional space.

The 'Scream' intro, on the other hand, seeks to circumvent these conventions, and I assume that it happens in an attempt to illustrate the song's lyrics. It is also an indication that mid-1990s' state of the art pop productions, using still more advanced digital recording, began to look for other aural conventions than the illusion of three-dimensionality. In fact, sometimes the whole notion of sound as necessarily inhabiting some kind of space is challenged, here by the LFDS and on the next full Jackson album, Invincible (2001), by some of the vocal stagings. ${ }^{13}$ But judging from the recordings, Jackson, his producers and Swedien did not want to go all the way. According to Swedien (2003), he maintained a 'bit' of the traditional stereo illusion:

I love to take a piece of music, and with it, create a recorded sound field, or sonic image, that could not possibly occur in a natural acoustic environment. [...] at the same time it has always been extremely important to me to have a bit of stark reality of sound buried somewhere on my work for the ear to relate to - to 'ground' the ear so to speak. (pp. 145-146)

In the last decade, even this last 'bit' has become still more challenged by a number of producers from, say, Max Martin to Madonna (and her collaborators) to Air (Walther-Hansen, 2009), reaching towards completely different kinds of spatiality by using still more sophisticated, digital hard- and software. Or as Virgil Moorefield describes it, 'recording's metaphor has shifted from one of the "illusion of reality" (mimetic space) to the reality of illusion (a virtual world in which everything is possible)' (2005, p. xiii).

But still the sound parameter appears to be a useful conceptualisation and systematisation for discussing many of the aural aspects of recordings. It might also be helpful in discussions of film soundtracks and sound designs. It may be used and elaborated upon in sophisticated ways by specialists, while non-specialists may be able to find a way to talk about music from the point they know best: its sound. 


\section{Notes}

1. Together with different producers, Bruce Swedien has worked as a recordist and mixer on all Michael Jackson albums from Off the Wall (1979) to Invincible (2001).

2. Lacasse defines vocal staging as 'any deliberate practice whose aim is to enhance a vocal sound, alter its timbre, or present it in a given spatial and/or temporal configuration with the help of any mechanical or electrical process, presumably in order to produce some effect on potential or actual listeners' $(2000$, p. 5).

3. According to Altman et al. most studies have focussed either on the spoken dialogue, the sound effects or the music. But he proposes to take all of it into account at the same time as a 'multiplane product' (2000, pp. 341,358). This is reflected in contemporary film productions, where sound designers responsible for a film's general sound are normally credited (Mancini, 1985, p. 361).

4. In an article on Jackson's 'Black or White' video the authors intend to do 'a "reading" of the Black or White video based upon both the visual and the musical elements' (Burnett \& Deivert, 1995, p. 20). Nevertheless, the sole comment on the musical elements reads like this: 'Musically, "Black or White" is not simply another dance song. It is a complex mixture of heavy metal, hard rock, rap, and a touch of funk, combined with a blues harmony and a pop melody' (ibid., p. 36). This mirrors the general balance between comments on visuals and sounds in both academic and journalistic texts on Michael Jackson. Swedish Olle Edström's short book on the release of Dangerous (1992) is one exception to this, as it contains short music-analytical comments on each of the album's songs, while Melissa Campbell's short article on Jackson's nonverbal vocalisations (2003) and Virgil Moorefield's comments on 'Billy Jean' (2005, pp. 85-89) are two other exceptions. Also, Popular Music and Society is about to release a special issue on Jackson's music following his death in 2009 - and more than 40 years after his initial breakthrough as a member of the Jackson Five.

5. The term itself comes from film production, where it designates an actual indoor stage used for the simultaneous recording of picture and sound (White \& Louie, 2005, p. 362). During the last 10-15 years sound stage has become common in audio circles to designate the illusionary, (two- or) three-dimensional space in recordings. Among the competing terms have been soundscape (Schafer, 1977, pp. 274-275), sound box (Moore, 2001, p. 121) and sound-field (Swedien, 2003, pp. 146-148). Originally, these terms referred to somewhat different phenomena, but they have been used to designate phenomena related to the sound stage as well.

6. Judging distance is a complex process. Distance is first and foremost given by the amount of timbral information and detail and sometimes also by the ratio between direct and indirect sound information (Moylan, 1992, pp. 218-219).

7. Zak uses the word recordist as a general term for anyone involved in the recording process, be it songwriters, performers, engineers or producers, and to denote overlaps among these roles (2001, p. xii).

8. Different combinations of sound carriers and playback systems sound somewhat differently. There is no ideal listening situation or set-up, but in order to at least partly overcome this I have listened to the music on several different stereo sets at different playback levels, changing between speakers (listening in the 'sweet spot') and headphones.

9. It might be heard as a mistake that happened because of the rush to re-mix and shorten the original master. 'The Lady in My Life' lost one verse in this process (Jones, 2001, pp. 238-239; Swedien, 2003, pp. 112-113). But the 2001 re-mastered edition of Thriller has the same changes, thus indicating that they may be intentional.

10. See Moore (2001, pp. 120-126) for descriptions of several different sound stages in the period from the 1960s to the 1980s.

11. Keyboard player and programmer Michael Boddicker interviewed in Rule (1995, p. 76). 
12. The guitar feedback is not indicated in figure 5 , because different playback equipment places the sound slightly to the right, but in very different places with regard to distance, ranging from near to the cup/plate to behind the clear synth sound.

13. Taking its cue from the chorus staging in 'The Lady in My Life', one example of the radical vocal staging is the chorus of 'Unbreakable'. An apt metaphor for describing this sound spatially might be the aural equivalent to a hall of mirrors.

\section{Discography}

Jackson, M. (1979). Off the Wall. New York: Epic.

Jackson, M. (1982). The Lady in My Life. On: Thriller. New York: Epic.

Jackson, M. (1982). Thriller. New York: Epic.

Jackson, M. (1987). Bad. New York: Epic.

Jackson, M. (1991). Black or White. On: Dangerous. New York: Epic.

Jackson, M. (1991). Dangerous. New York: Epic.

Jackson, M. (1995). Scream. On: HIStory. New York: Epic.

Jackson, M. (1995). HIStory. New York: Epic.

Jackson, M. (2001). Unbreakable. On: Invincible. New York: Epic.

Jackson, M. (2001). Invincible. New York: Epic.

\section{References}

Altman, R. with Jones, M., \& Tatroe, S. (2000). Inventing the Cinema Sound Track: Hollywood's Multiplane Sound System. In: Buhler, J., Flinn, C., \& Neumeyer, D. (Eds.), Music and Cinema (pp. 339359). Hanover and London: Wesleyan University Press.

Burnett, R., \& Deivert, B. (1995). Black or White: Michael Jackson's Video as a Mirror of Popular Culture. Popular Music and Society, 19(3), 19-40.

Campbell, M. (2003). Saying the Unsayable: The Non-Verbal Vocalisations of Michael Jackson. Context, 26, 17-26.

Doyle, P. (2005). Echo and Reverb: Fabricating Space in Popular Music Recording 1900-1960. Middletown (CT): Wesleyan University Press.

Edström, O. (1992). Michael Jackson:Dangerous och dess mottagande [Michael Jackson: Dangerous and its Reception]. Göteborg: Musikvetenskap, Göteborg University.

Johnson, M. (1987). The Body in the Mind: The Bodily Basis of Meaning, Imagination, and Reason. Chicago and London: University of Chicago Press.

Jones, Q. (2001). The Autobiography of Quincy Jones. London: Hodder \& Stoughton.

Katz, M. (2004). Capturing Sound:How Technology has Changed Music. Berkeley, Los Angeles and London: University of California Press.

Lacasse, S. (2000). Listen to My Voice: The Evocative Power of Vocal Staging in Recorded Rock Music and Other Forms of Vocal Expression (Doctoral dissertation). University of Liverpool. Accessed 13 October 2010 on: http://www.mus.ulaval.ca/lacasse/ texts/THESIS.pdf

Lakoff, G., \& Johnson, M. (1980). Metaphors We Live By. Chicago and London: Chicago University Press. LaRue, J. (1970). Guidelines for Style Analysis. Warren, Michigan: Harmonie Park Press.

Mancini, M. (1985). The Sound Designer. In: Weis, E., \& Belton, J. (Eds.), Film Sound: Theory and Practice (pp. 361-368). New York: Columbia University Press.

Popular Music and Society (forthcoming special issue on Michael Jackson). 
Michelsen, M. (1997). Sprog og lyd $i$ analysen af rockmusik [Language and Sound in the Analysis of Rock Music] (Doctoral dissertation). University of Copenhagen. Accessed 12 December 2011 on: http://www.staff.hum.ku.dk/momich/afhandling.pdf

Michelsen, M. (forthcoming). Leave Me Alone: Michael Jackson's Angry Voice. Danish Musicology Online. Accessed on: http://www.danishmusicologyonline.dk/

Moore, A. (2001). Rock: The Primary Text. Developing a Musicology of Rock (2nd ed.). Aldershot, UK and Burlington, US: Ashgate.

Moorefield, V. (2005). The Producer a Composer: Shaping the Sounds of Popular Music. Cambridge, MA and London: MIT Press.

Moylan, W. (1992). The Art of Recording: The Creative Resources of Music Production and Audio. New York: Van Rostrand Reinhold.

Moylan, W. (2008). Considering Space in Music. Proceedings from the 2008 Art of Record Production Conference. Accessed on: http://www.artofrecordproduction.com

Rumsey, F. (2002). Spatial Quality Evaluation for Reproduced Sound: Terminology, Meaning, and a Scene-Based Paradigm. Journal of the Audio Engineering Society, 50(9), 651-666.

Rule, G. (1995). Behind the Scenes with M.J.'s Dream Team [interviews with Steve Porcaro, Michael Boddicker, Jason Miles, Jeff Bova, Andrew Scheps]. Keyboard, 11, 75-84.

Schafer, R.M. (1977). The Tuning of the World. New York: Alfred A. Knopf.

Swedien, B. (2003). Make Mine Music. N.c.: MIA Musikk.

Toulson, E.R. (2006). A Need for Universal Definitions of Audio Terminologies and Improved Knowledge Transfer to the Audio Consumer. In: Proceedings from the 2006 Art of Record Production Conference. Accessed on: http://www.artofrecordproduction.com

Walther-Hansen, M. (2009). The Influence of Music Technology on the Perception of the Performer in Phonographic Space. In: Proceedings from the 2009 Art of Record Production Conference. Accessed on: http://www.artofrecordproduction.com

White, G.D., \& Louie, G.J. (2005). The Audio Dictionary (3rd ed.). Seattle: University of Washington Press. Zagorski-Thomas, S. (2005). Shouting Quietly: Changing Musical Meaning by Changing timbre with Recording Technology [Paper delivered at the Conference for Interdisciplinary Musicology (CIM05), Montréal, Canada, 10-13 March, 2005].

Zagorski-Thomas, S. (2006). Functional Staging Through the Use of Production Techniques in late 20th Century African and Cuban Popular Music Recordings. In: Proceedings from the 2006 Art of Record Production Conference. Accessed on: http://www.artofrecordproduction.com

Zagorski-Thomas, S. (2008). The Musicology of Record Production. Twentieth century music, 4(2), 189207.

Zak, A.J. (2001). The Poetics of Rock: Cutting Tracks, Making Records. Berkeley and Los Angeles: University of California Press. 